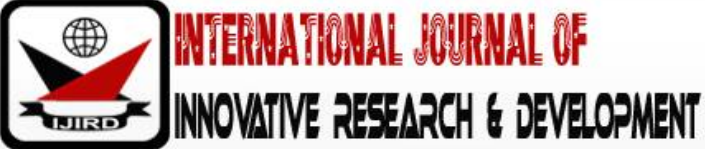

ISSN 2278 - 0211 (Online)

\section{Social-Cultural Impact of Bead work in East Africa: the Nexus between the Dinka, Samburu \& Masaai Ethnicities}

\author{
Mercy Mwihaki Nguru \\ Postgraduate Student, Department of Art and Design, University of Nairobi, Kenya \\ Dr. Samuel Mwituria Maina \\ Senior Lecturer, School of the Arts and Design, University of Nairobi, Kenya
}

\begin{abstract}
:
Beadwork has been practiced in Africa and worldwide for centuries. In East Africa, different communities made beads from a wide range of materials available to them. This materials range from black coral collected from the Indian Ocean to the use of bone from their livestock. This study is an analysis of beadwork uses in the following East African communities; Dinka of South Sudan, Maasai of Kenya and Tanzania, and the Samburu of Kenya. Conducted in Nairobi, the objective was to establish its social-cultural significance as an art form. It was also a part of the annual design symposia, workshops and presentations involving master's students, faculty, experts and stakeholders. The research used an interview guide, observation and a historical research method. The findings established that beadwork was used for social, cultural and religious practices in all the communities. These include, rites of passage, decoration and ornamentation, and also for political and leadership purposes. Despite the similarities in occasions, the types, and colors of beads used differed. The findings further pointed out the unique characteristics in color, materials, shape of beads in each community.
\end{abstract}

Keywords: Beadwork, social, cultural, impact, East Africa

\section{Introduction}

East African bead work is used to adorn the body, for decoration and has been used as a symbolic feature for many years to signify age, marital status and also as a symbol of wealth among many east African communities. An example is the Dinka corsets. Beadwork has also been used for rituals (Nyambura, 2013). Different colors, shapes, material and sizes are used to represent different aspects of the wearer and may differ from one community to another. Beads have been made in East Africa for centuries, but were made popular during the Arab trade that was favored by the Monsoon winds. Nyambura explains that glass beads were imported in plenty making beadwork for diverse use very popular. Beads became a source of income and a form of currency.

\section{Theory}

Beads in Africa have over time earned the name trade beads due to the fact that they were used in the exchange of goods and also as a form of currency. The earliest beads date back more than 12000 years. The oldest beads to be discovered in Africa were found in Libya around the year 10000Bc. They were disc shapes made from ostrich eggs. Similar beads were discovered in Sudan's Neolithic sites while other ancient beads have been found in Kalahari Desert (Carll, 2014).

Carl (2014) goes on to describe beads of Africa as being heavily dependent on environmental factors, the availability of raw materials and external influences. This influence has been from the Europeans and Islamic culture along East Africa due to a long exposure to the Arab world. Clear Arabic influence has been manifested to date in different forms from architecture and textile to bead work and cuisines (Rhodia, 2012).

Intricate beadwork designs from Egypt were discovered in the 1500BC (Marcus, 2014). The Egyptian artisans depicted images of gods and kings wearing broad collars with intricate beadwork on them. Rhodia (2012) explains that the earliest beads were made from shell, bone, horn, teeth, seed, wood, ivory and other materials. Beads from such materials are still used in the continent. Cowrie shell discs (FIGURE 1) were used as a form of currency throughout Africa and were also used to adorn the human body (Nyambura, 2013). Rhodia (2012) confirms that in Sudan, beads were made from the back coral available on their shoreline to make beautiful black beads in different shapes and sizes.

It is important to note that, in the first Millennial BC the making of stone beads sprouted in Nigeria. The beads were made from the red jasper rock. The beads were made in cylindrical shapes and were double drilled (FIGURE 2). In Mali, stone beads were cut from granite and green amazonite (Kiyoshi, 2001).

Diverse East African communities used beads to signify different aspects in their culture, while maintaining uniqueness in design and physical appearance. From the year 1480, the mass export of beads from Europe to East Africa 
started from Venice and Murano in Italy, Bohemia and the Netherlands. By the late 19th century, a large quantity of beads was already in useas trade goods in many parts across the continent (Rhodia, 2012).

In Kenya, the earliest excavations were found in Manda Island in the north coast (Rhodia 2012). They consisted of fragments of bowls, flasks and beads. These indicate a long history of importation along the east African coast dating to the mid-ninth century. Beads found were crystal, coral beads, and agates according to (Roberts, 1985).

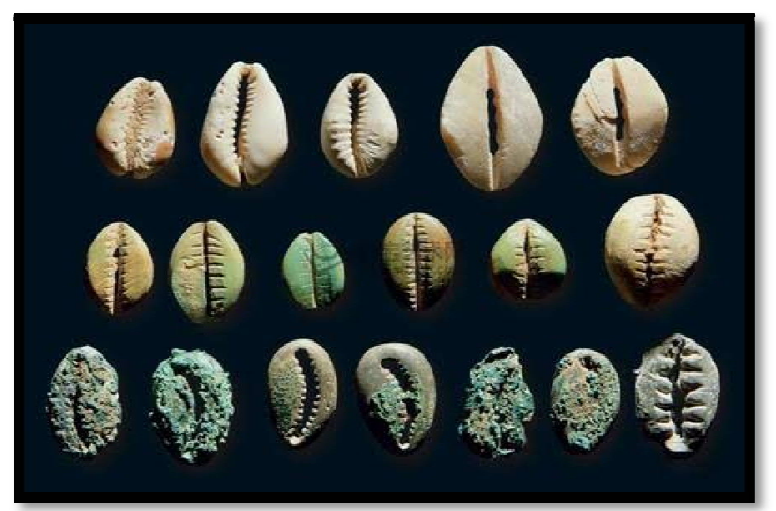

Figure 1: Ancient Cowry Shell Discs

Source: Hillerdrygoods.Com 11/10/2019

Figure 2 shows ostrich egg shells used by the Turkana community of Kenya. They are still used to-date and the practice of making these beads is still done in some communities in South Africa.

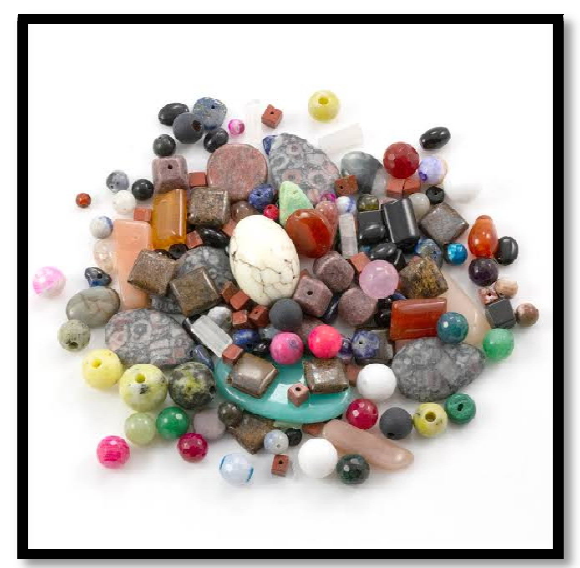

Figure 2: An Assortment of Glass Beads Source: Target.Com

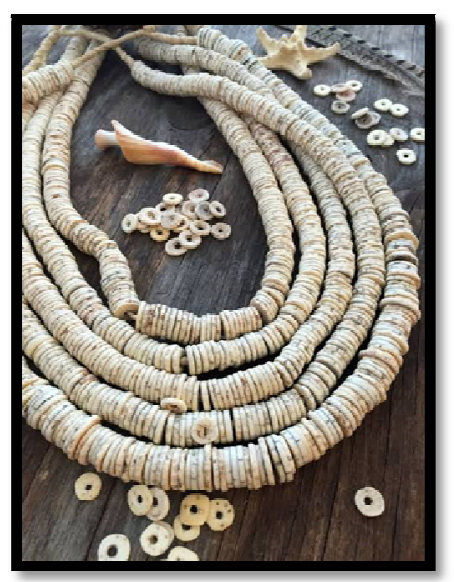

Figure 3: Ostrich Egg Beads by the Turkana Source: Target.Com 24/10/2019

Beads were used to decorate African art such as masks that were used for religious practices in many parts of Africa. Such masks were worn to transform the wearer into a spirit. Beads were attached on the masks surfaces for example the Mende people of Sierra Leone (FIGURE 4). Beads were also used to decorate textile. They are still a great part of East African modern design and are stillused for traditional purposes in many communities in present day like the Maasai of Kenya See (FIGURE 5). 


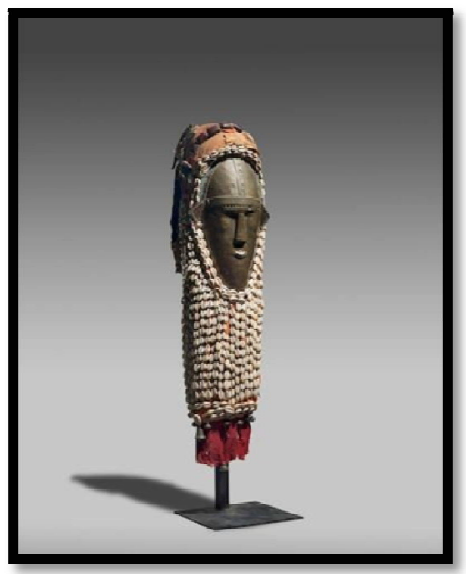

Figure 4: Mende Sierra Leone Mask Sources: Bonhams.Com 1/11/2019

Communities in east Africa that stand out in bead work include the Maasai of Kenya and Tanzania, Dinka of Sudan and Samburu of Kenya.

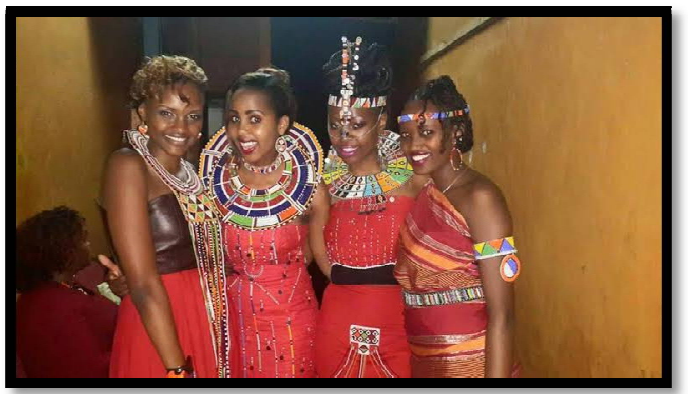

Figure 5: Two Women (Center) Wearing Bead Decorated Dresses Source: Facebook.Com 10/10/2019

Beads were used for a wide range of activities and to symbolize different aspects in communities across Africa (Nyambura, 2013). Beads communicated the qualities of a person's social, political, religious and artistic nature. Traditionally beads were used as bride price especially cowry shells, they were also used to distinguish between age groups and people at different developmental stages. Beads were also incorporated during ceremonies and rituals such as the rites of passage

\subsection{Case Studies}

\subsubsection{Samburu}

The Samburu is a Nilotic community in Northern Kenya. In this culture, bead-work was done mainly by women and young girls (Rhodia, 2012). Both men and women wear beaded necklaces, bangles and anklets in multiple layers. (Nyambura 2013) confirms that the first periodic beads market in Samburu District of Kenya was established in Maralal town in 1991.

Married Samburu women wore a big collar called the mporo, which was made of a giraffe's tail hair. It was decorated using dark pink glass beads placed down the center (Figure 6). The mporo signified marital status from when a young girl is betrothed (Bilinda, 2002). Just before a girl is married her mother gifts her with beads from her own mporo and later other female relatives and fellow women gift her more of the mporo beads. On the same issue (Juvik, 2017) beads symbolize wealth and fertility and also serve as a direct link to ancestors. A sample of the mporo is stored at the African Heritage house museum. 


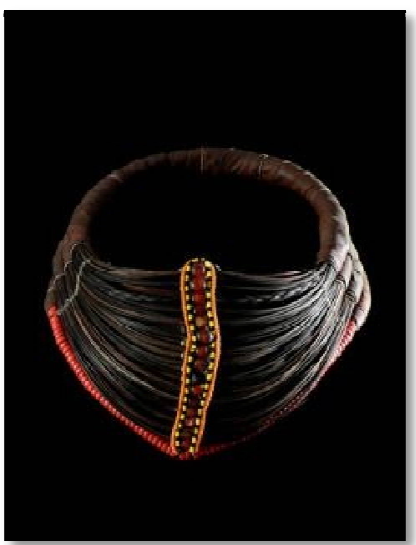

Figure 6: A Samburu Mporo

Source: Africaandbeyond.Com 24/10/2019

Young girls who had reached puberty were also gifted with layers of beads made into discs to wear around their necks. Figure 7 shows a young girl wearing beads obtained from betrothal gifts.

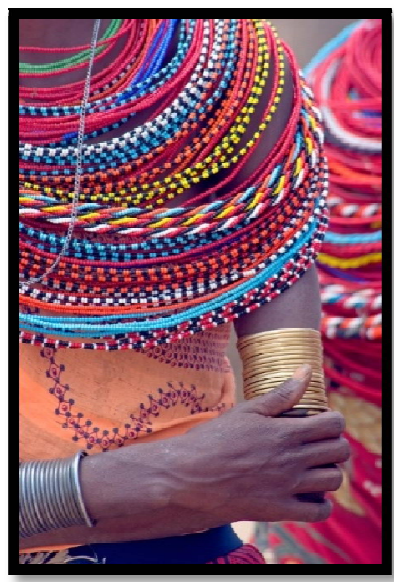

Figure 7: A Young Girl Soon to Be Married Source: Fineartamerica.Com 1/11/2019

During circumcision the mothers to the circumcised boys wore black and white beads. These signified that their sons had entered into adulthood and were members of the Moran (Ahlstedt, 2012) Beads were also used for a cultural practice called beading where warriors gift beads to young girls as sign of a non-marital sexual relationship between Samburu men in the worrier age group. Ahlstedt (2012) continues to explain that most of the girls are only about 15 years old. This is a negative practice to these young women who end up dropping out of school, pregnant and alone. NGOs and the government of Kenya have put efforts towards eradication of this practice among the Samburu (Figure 8).

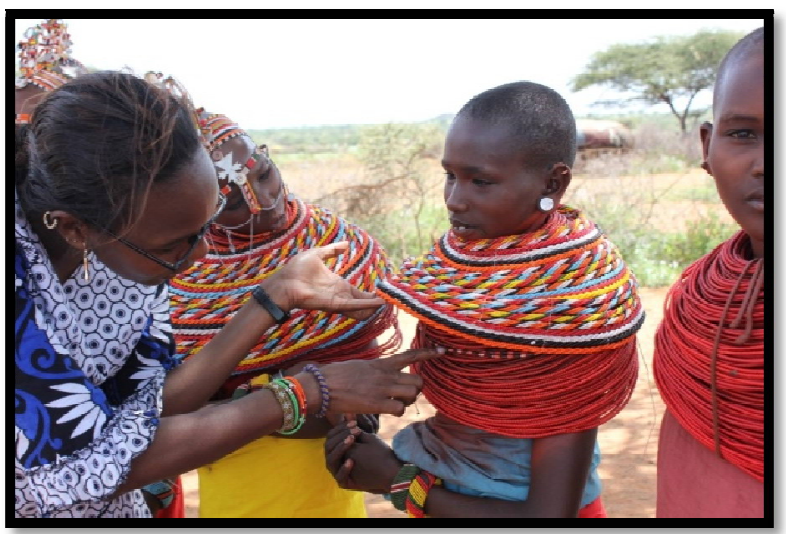

Figure 8: Jane A Member of the Samburu Women Trust and a Beaded Girl Source: Kiosfoundation.Com 25/10/2019

\subsubsection{TFE Dinka}

Beads were popular in Sudan for adornment (Rhodia 2012). They were creative in their materials due to scarcity. Black coral was scattered on the Sudan shore, hence it was popularly used to create heavy bracelets, earrings and pendants. Even so, no record exists about it being used to create beads. Beads among this community were used for 
aesthetic purpose similar to other east African communities. Colorful beads were believed to be a great source of beauty and adornment.

The Dinka people in specific wore Corsets (figure 9) made out of thousands of decorative glass beads. An ancient Dinka corset can be found at the African Heritage House in Kenya. The corsets are made of various colors and are supported by strong wires at the spine. Both men and women wore the corsets (Figure 10).

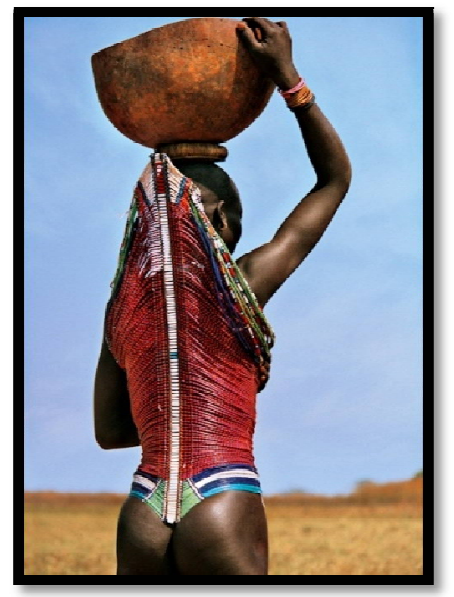

Figure 9: A Dinka Woman Wearing the Corset Source: Pinterest.Com 20/10/2019

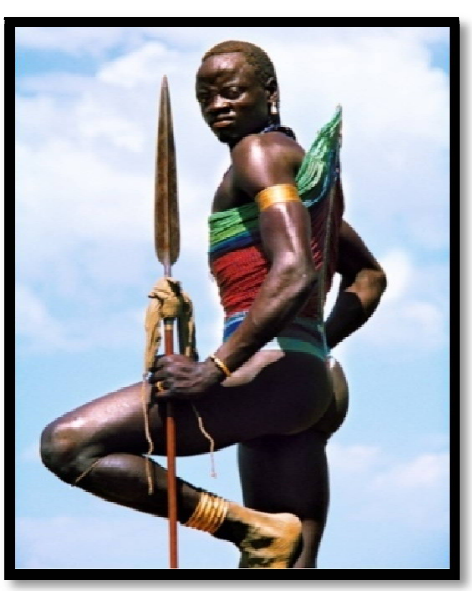

Figure 10: A Dinka Man Wearing the Corset Source: Zoede.Com 12/10/2019

These corsets symbolize a lot about the wearer such as the age, wealth and social status, gender and even ethnic affiliation. Gender; among the Dinka community corsets were worn by both men and women (Kowalski, 2012). Male corsets had a projection at the spine similar to those worn be younger girls.

Wealth; the larger the projection at the spine of the corset the wealthier the family the man came from. The Dinka also wore beaded wedding necklaces around their necks. Women's corsets were different from those of men and were decorated with cowry shells to attract the men. They also were looser and hang from the neck figure 11 and figure 12.

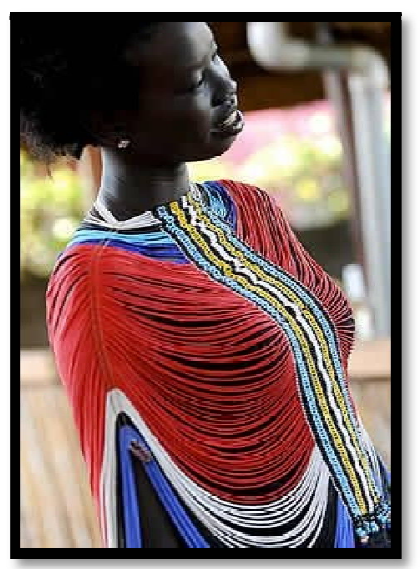

Figure 11: A Married Dinka Woman in Her Corset Source: Lipstickalley.Com 12/10/2019 


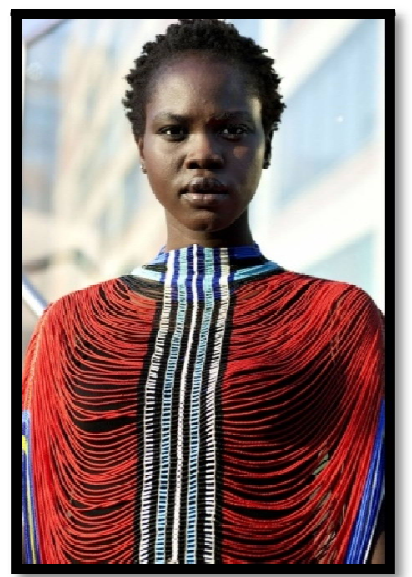

Figure 12: Front View of A Married Woman Corset

Source: Lipstickalley.Com 14/10/2012

Age; different colors of beads have been used to symbolize different age groups in the Dinka community. Those between the ages of 15 years to 25 years old wore corsets made of black and red beads. Pink and purple beads were worn by people between the ages of 25 years to 30 years while yellow beads were worn by people above the age of 30 years (Carll, 2014).

Rites of passage; men retain their corsets on their bodies until they move from one age group to the next. Younger women wear their corsets until it is cut open on their wedding day (Kowalski, 2012). The Dinka corset has inspired the fashion corset and has been show cased in international runways for example in the Victoria Secrets Fashion Show FIGURE 12. Allan Donavan (personal interview, 2019) confirmed that The Lion King movie had costumes inspired by the Dinka corset in its first production. The corset is very expensive and retails for about USD 550. At the African heritage, an ancient Dinka corset is displayed. It was donated by the Dinka when he visited south Sudan.

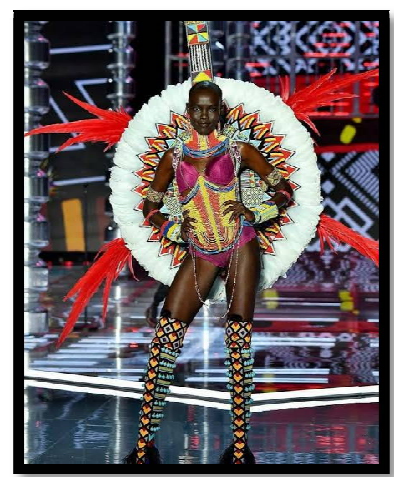

Figure 13: A Victoria Secret Model Wearing a Dinka Corset Source: Victoriasecret.Com 10/10/2012

\subsubsection{Maasai of Kenya and Tanzania}

Among the Maasai community, beads are an essential component of everyday dress they are worn around their necks in intricate patterns and designs. Beads used are often very bright in color with red (Figure 14) yellow and brown being the most dominant colors. Red is particularly significant among the Maasai community as it's their appreciation to the soil (Parrot, 1972).

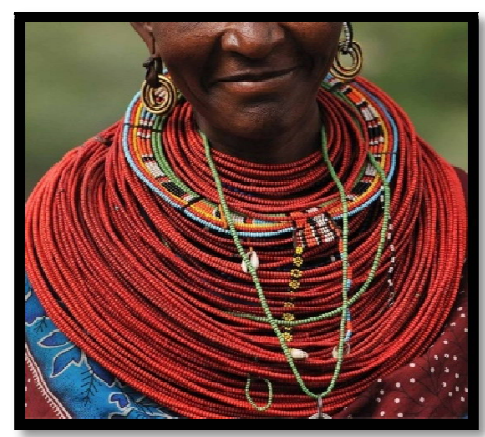

Figure 14: A Maasai Lady Wearing Laters of Beads Source: Myilava.Com 21/10/2019 

following;

The Maasai wear a large number of bracelets and anklets. Beadwork is done by women. Beads are used for the

Aesthetics; Beadwork is used to make head adornment that have hanging steel from them that make noises during their traditional dance. These headgear is a great source of beauty to the wearer and worn during modern day Maasai weddings.

Marital status; unmarried Maasai girls adorned themselves with an enormous round beaded disc around their necks. This was used during cultural dances to help show their grace and flexibility that was desirable to men in the community. Married women wore long necklaces decorated with blue beads.

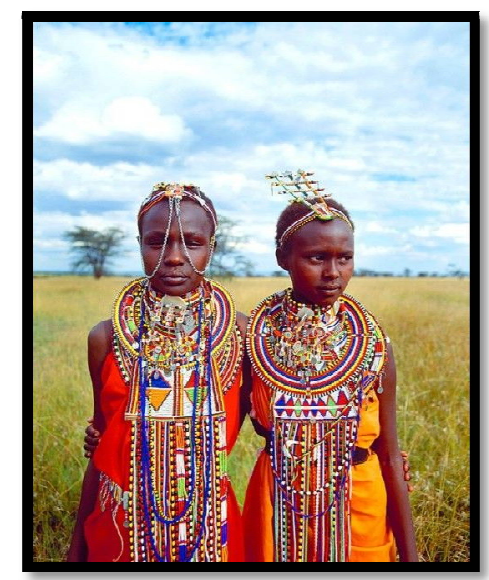

Figure 15: Two Unmarried Maasai Girls Source: Maabeadwork.Com 12/10/2019

Social status; individuals in the community who were wealthier wore more intricate bead designs (figure 15). They also wore more colorful beads compared to those who weren't as wealthy. Young Maasai girls who were engaged wore necklaces made from beaded intertwined strings signifying the union between two people that was made by their mothers. The Maasai used beads to decorate their shield with geometric shapes (Parrot, 1972). Among the Maasai, different colored beads signify different special meanings, for example red signifies blood. Blue represents energy. Green 'the color of grass' represents the color of land and productivity. White represents peace like in many other tribes and purity. Lastly black represent the people (Thompson, 2016). On the same issue (Wijngaarden, 2017) indicates that yellow symbolizes the sun, fertility and growth.

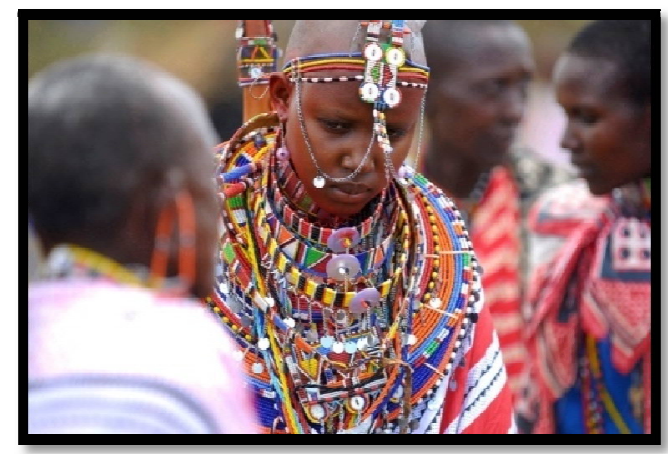

Figure 16: A Maasai Lady with Multiple Bead Layers Ingicating Wealth Source: Dreamstime.Com 26/10/2019

\section{Method}

This research study employed a desktop exploratory critical review of the subject. This historical research looked into already existing artifacts and reports. A large number of documents were examined, analyzed and the data recorded. Different aspects of the artifacts were discussed and contextualized through group discussions and expert analysis. This enabled the researcher to identify the social impact of beads in the communities mentioned above. A site visit of the African heritage house was also conducted. It houses a large number of beadworks from around the continent that the owner, Allan Donavan collected when traveling around the world.

\section{Findings}

Beads are an integral part of the communities under study. There is common ground on what the beads were used. For example, religious ceremonies, rites of passage, and community affiliation. The Dinka corset stands out from the Turkana 'mporo'. All the items vary including materials used. This shows the uniqueness and creativity of the communities in east Africa. 
It is also important to note the different meaning of colors in beads per community. The Maasai, Dinka and Samburu identify color and use it for symbolism. And each color has a unique meaning in the community. The symbols represented by each color are from their daily to daily activities and from nature. For example, the Maasai use green to symbolize grass.

\section{Conclusion}

From the research, it was established that the East African region is rich in art and design from the diverse number of communities. Beadwork from east Africa has permeated all continents and has been stored in museums. At the African Heritage House, for example, you can see all the beads, textiles and arts from East Africa. Beads from all over the rest of the continent are displayed as creative and elaborate pieces in this museum. Beads have been used for similar occasions and ceremonies in many communities even if colors, sizes, and materials may slightly differ from one community to another; the bottom line seems to be that beads are symbolic in the east African region. They are more than just beads of trade and beads just for decorative purposes. Rites of passage among East African community have incorporated the use of beads more than any other social occasions.

\section{References}

i. Suzanne Blier: 'Africa, Art, and History: An Introduction', A History of Art in Africa, pp.

ii. 'Art \& Life in Africa - The University of Iowa Museum of Art'. uiowa.edu. Archived from the original on 2013-0630. Retrieved 2019-10-23.

iii. A History of Art in Africa (2001) Monica Blackmun Visonà et al. Prentice Hall, New York.

iv. Tinga Art: Contemporary East African Art

v. Ahlstedt, M (2012). From Samburu Heirloom to New Age Artifact: The Cross-Cultural Consumption of Mporo Marriage Beads Bilinda Straight: American Anthropological Association

vi. Carll H. de Silver (2014).Arts of Africa

vii. Caleb, B (1994). The Art of the African Mask Bayly Art Museum, University of Virginia.

viii. Kino, Carol (2012). 'When Artifact 'Became' Art'. The New York Times. Retrieved October 17, 2019.

ix. Kowalski, K (2012). Kiafrika the Dinka corset

X. Marcus. E'Broad Collar’. Retrieved 17 October, 2019.

xi. Parrot, F. J. (1972).Introduction to African arts of Kenya, Zaire, and Nigeria. New York: Acro Publishing Company.

xii. Rhodia. M. (2012).Ushanga: The Story of Beads in Africa. Nairobi Kenya: Desert Sand Ltd.

xiii. Roberts. A, (1984).Manda: Excavations at an Island Port on the Kenya Coast by Neville Chittick British Institute in Eastern Africa (memoir no. 9), Nairobi: Thames and Hudson, London

xiv. Nyambura, R (2013). The economic utility of beads culture of the Samburu tribe of Kenya.

xv. Togashi. K, Dubin. S (2001).The Worldwide History of Beads: Ancient. Ethnic. Contemporary Paperback

xvi. Thompson, S (2016). Things you didn't know about maasai beadwork. Accessed September 22, 2019 from thomsonsafaris.com

xvii. Wijngaarden, V (2017).Maasai beads: the interplay between Europe and Africa Retrieved October 5, 2019 from theconversation.com

xviii. Juvik, H (2017). Featured Object: Mporro, Married Woman's Necklace. Accessed on October 2017 from spurlock.illinois.edu 